Chapman University

Chapman University Digital Commons

Pharmacy Faculty Articles and Research

School of Pharmacy

$12-1-2013$

\title{
Synthesis of Novel Ciprofloxacin Analogues and Evaluation of Their Anti-Proliferative Effect on Human Cancer Cell Lines
}

\author{
Narva Suresh \\ Birla Institute of Technology w Science \\ Hunsur Nagendra Nagesh \\ Birla Institute of Technology \& Science \\ Kondapalli Venkata Govri Chandra Sekhar \\ Birla Institute of Technology \& Science \\ Anil Kumar \\ Birla Institute of Technology \& Science \\ Amir Nasrolahi Shirazi \\ Chapman University, shirazi@chapman.edu \\ See next page for additional authors
}

Follow this and additional works at: http://digitalcommons.chapman.edu/pharmacy_articles

8 Part of the Cancer Biology Commons, Chemicals and Drugs Commons, Oncology Commons, and the Pharmacy and Pharmaceutical Sciences Commons

\section{Recommended Citation}

Suresh N, Nagesh HN, Sekhar KVGC, Kumar A, Shirazi AN, Parang K. Synthesis of novel ciprofloxacin analogues and evaluation of their anti-proliferative effect on human cancer cell lines. Bioorg. Med. Chem. Lett. (2013);23:6292-6295. doi: 10.1016/

j.bmcl.2013.09.077 


\section{Synthesis of Novel Ciprofloxacin Analogues and Evaluation of Their Anti- Proliferative Effect on Human Cancer Cell Lines}

\section{Comments}

NOTICE: this is the author's version of a work that was accepted for publication in Bioorganic \& Medicinal Chemistry Letters. Changes resulting from the publishing process, such as peer review, editing, corrections, structural formatting, and other quality control mechanisms may not be reflected in this document. Changes may have been made to this work since it was submitted for publication. A definitive version was subsequently published in Bioorganic \& Medicinal Chemistry Letters, volume 23, in 2013. DOI: 10.1016/j.bmcl.2013.09.077

The Creative Commons license below applies only to this version of the article.

\section{Creative Commons License}

\section{(c) 1 (1) 90}

This work is licensed under a Creative Commons Attribution-Noncommercial-No Derivative Works 4.0 License.

\section{Copyright}

Elsevier

\section{Authors}

Narva Suresh, Hunsur Nagendra Nagesh, Kondapalli Venkata Govri Chandra Sekhar, Anil Kumar, Amir Nasrolahi Shirazi, and Keykavous Parang 


\title{
Synthesis of novel ciprofloxacin analogues and evaluation of their anti-proliferative effect on human cancer cell lines
}

\author{
Narva Suresh ${ }^{\text {a }}$,Hunsur Nagendra Nagesh ${ }^{\mathrm{a}}$, Kondapalli Venkata Gowri Chandra \\ Sekhar $^{a, *}$, Anil Kumar ${ }^{\mathrm{b}}$, Amir N. Shirazic, Keykavous Parang \\ ${ }^{a}$ Department of Chemistry, Birla Institute of Technology \& Science-Pilani, Hyderabad Campus, \\ Jawahar Nagar, Hyderabad - 500 078, Andhra Pradesh, India. \\ ${ }^{b}$ Department of Chemistry, Birla Institute of Technology \& Science, Pilani- 333031, Rajasthan, India \\ ${ }^{\mathrm{c}}$ Department of Biomedical and Pharmaceutical Sciences, College of Pharmacy, University of Rhode \\ Island, Kingston 02881, USA
}

\begin{abstract}
:
A series of twenty two novel 1-cyclopropyl-6-fluoro-4-oxo-7-(4-substitutedpiperazin-1-yl)1,4-dihydroquinoline-3-carboxylic acid analogues have been synthesized, characterized $\left({ }^{1} \mathrm{H}\right.$ NMR, ${ }^{13} \mathrm{C}$ NMR and LCMS) and evaluated for their inhibitory activity on the proliferation of human caucasian acute lymphoblastic leukemiacells (CCRF-CEM), breast adenocarcinoma cells (MDA-MB-468) and human colon carcinoma cells (HCT-116). Among all the synthesized ciprofloxacin analogues $3 \mathrm{t}$ at $50 \mu \mathrm{M}$ showed comparable potency to doxorubicin $(10 \mu \mathrm{mol})$ in all three cell lines and 3j inhibited proliferation of MDA-MB-468 up to 35\% selectively over other two cell lines. Cancer is a leading cause of death worldwide. It is a group of diseases characterized by uncontrolled growth. Cancer is the second cause of death in the US. ${ }^{1}$
\end{abstract}

Ciprofloxacin (CP) is one of the broad-spectrum fluoroquinolone (FQ) antibiotics with low side effects. ${ }^{2} \mathrm{CP}$ exhibited antiproliferative and apoptotic activities in several cancer cell lines such as hormone resistant prostate cancer (HRPC) cell line (PC-3) ${ }^{3}$, transitional cell carcinoma cell lines (MBT-2 and T24) ${ }^{4}$, colon carcinoma cell lines (CC-531,SW-403 and HT-29) ${ }^{5}$, human lymphoidal cell lines (Jurkat) ${ }^{6}$, non-small-cell lung cancer cell line (NCI-H460 and A549) ${ }^{7,8}$, ovarian cancer cell line (CHO AA8) ${ }^{9}$, murine glioma cell line (GL26) ${ }^{10}$, bladder cell line (HTB9). CP was also found to exhibit cell cycle arrest at the $\mathrm{S} / \mathrm{G}_{2}-\mathrm{M}$ checkpoints. ${ }^{11}$

${ }^{*}$ Corresponding author:

Tel.: +91-40-66303527; E-mail: kvgc@ @yderabad.bits-pilani.ac.in, kvgcs@yahoo.com 
Along with $\mathrm{CP}$, other FQ derivatives like ofloxacin, levofloxacin, enoxacin and fleroxacin were shown to inhibit the growth of transitional cell and bladder carcinoma cell lines. ${ }^{2} \mathrm{CP}$ enhanced the antiproliferative effect of 5 -fluorouracil ${ }^{12}$, used for treatment of colon cancer. ${ }^{13}$ FQs inhibit the activity of mammalian DNA topoisomerases I, II and DNA polymerase enzymes involved in supercoiling, transcription, replication and chromosomal separation of prokaryotic DNA. $^{5,14}$

Many reports indicate, antitumor efficacy of $\mathrm{FQs}$ can be augmented by increasing the lipophilicity of compounds. ${ }^{2,15,16}$ Introducing substituents at C-7 position of camptothecin improved the lipophilicity and this led to the discovery of gimatecan, which is currently in phase II clinical trials. ${ }^{17}$ In bis-quinolinium compounds, lipophilicity of the substituent enhanced their antiproliferative activity against HT-29 colon cancer cell line. ${ }^{18}$ Structure of FQ derivatives as anticancer agents is depicted in figure 1. ${ }^{19-21}$

$\mathrm{CP}$ showed antiproliferative and apoptotic activities on prostate cancer cell lines (PC3) but not on non-tumorigenic prostate epithelial cells (MLC8891). ${ }^{22} \mathrm{CP}$ can impede the acute and chronic prostate inflammation which is responsible for prostate cancer development. ${ }^{23}$ Fruitful anticancer results of lipophilic derivatives of $\mathrm{CP}$ have attracted us to investigate new lipophilic derivatives of $\mathrm{CP}$ as antitumor agents. Hence, we impelled our research work and synthesized new FQ derivatives as antitumor agents. In the current study, we synthesized 7-(substituted piperazin-1-yl) derivatives of CP. Firstly, 7-(4-(2-chloroacetyl)piperazin-1-yl)-1-cyclopropyl-6fluoro-4-oxo-1,4-dihydroquinoline-3-carboxylic acid(2)was synthesized by coupling CP with chloroacetyl chloride as reported earlier ${ }^{2}$ and then various substituted piperazines were reacted with 2 to enhance the lipophilicity (Scheme 1).

Acylation of $\mathbf{C P}, \mathbf{1}$ with chloroacetyl chloride in $\mathrm{CH}_{2} \mathrm{Cl}_{2}$ yielded compound $\mathbf{2}$ in $70 \%$ after purification. ${ }^{2}$ The series of 1-cyclopropyl-6-fluoro-4-oxo-7-(4-substituted piperazin-1-yl)-1,4dihydro quinoline-3-carboxylic acid derivativesof $\mathbf{C P}$ were prepared by coupling commercially available substituted piperazines with $\mathbf{2}$ in $N, N$-dimethylformamide (DMF) to obtain the final compounds 3a-v in yields ranging from $55-95 \% .^{24}$ (Scheme 1, Table 1)

The synthesized compounds were evaluated for their inhibitory activity on the proliferation of three cancer cell lines vizhuman caucasian acute lymphoblastic leukemiacells (CCRF-CEM), breast adenocarcinoma cells (MDA-MB-468) and human colon carcinoma cells (HCT-116). Doxorubicin (Dox) and DMSO were used as positive and negative controls, respectively. The 
results for the antiproliferative activity of the synthesized ciprofloxacin analogues $\mathbf{3 a - v}$ at $50 \mu \mathrm{M}$ after $72 \mathrm{~h}$ incubation are shown in Figure 2. Most of the synthesized CP analogues were not as effective as positive controlin inhibiting the proliferation of these cell lines after 72 hincubation. Among all the CP analogues,3j inhibited proliferation of MDA-MB-468 up to $35 \%$ and compounds3s and $3 t$ with fluoro substituent inhibited proliferation of all three cancer cell lines in the range of $35-60 \% .3 \mathrm{t}$ at $50 \mu \mathrm{M}$ showed comparable potency to doxorubicin $(10 \mu \mathrm{mol})$ in all three cell lines.

In summary, twenty two novel CP analogues were synthesized emphasizing on lipophilicity over two steps and evaluated for their anticancer activity on human caucasian acute lymphoblastic leukemiacells (CCRF-CEM), breast adenocarcinoma cells (MDA-MB-468) and human colon carcinoma cells (HCT-116). Among the synthesized ciprofloxacin analogues, 3t (fluoro substituent) at $50 \mu \mathrm{M}$ showed comparable potency to doxorubicin $(10 \mu \mathrm{mol})$ in all three cell lines, while 3j (without fluoro substituent) inhibited proliferation of MDA-MB-468 up to 35\% selectively over other two cell lines. These results reveal the importance of fluoro substituent and further modification on the chemical structure of $\mathrm{CP}$ derivatives could lead to the synthesis of a promising candidate to develop anti-cancer agent.

\section{Acknowledgements}

We acknowledge the financial support from University Grants Commission (UGC), Government of India, New Delhi. NS thanks UGC, New Delhi for the award of research fellowship.

\section{References and notes}

[1] Cancer Facts and Figures. American Cancer Society, 2012.

[2] Azema, J.; Guidetti, B.; Dewelle, J.; Le Calve, B.; Mijatovic, T.; Korolyov, A.; Vaysse, J.; Martino, M. M.; Martino, R.; Kiss, R. Bioorg. Med. Chem. 2009, 17, 5396.

[3] El-Rayes, B. F.; Grignon, R.; Aslam, N.; Aranha, O.; Sarkar, F. H. Int. J. Oncol. 2002, $21,207$.

[4] Ebisuno, S.; Inagaki, T.; Kohjimoto, Y.; Ohkawa, T. Cancer. 1997, 15, 2263.

[5] Herold, C.; Ocker, M.; Ganslmayer, M.; Gerauer, H. Hahn, E.G.; Schuppan, D. Br. J. Cancer. 2002, 86, 443. 
[6] Kozeil, R.; Szczepanoswska, J.; Magalska, A.; Piwocka, K.; Duszynski, J. ; Zablock, K. J. Physiol. Pharmacol. 2010,61, 233.

[7] Mondal, E. R.; Das, S. K.; Mukherjee, P.Asian Pacific J Cancer Prev. 2004, 5, 196.

[8] kloskowski, T.; Gurtowska, N.; Olkowska, J.; Marcin Nowak, J.; Adamowicz, J.; Tworkiewicz, J.; Debski, R.; Grzanka, A.;Drewa, T. Int. J. Oncol. 2012, 41, 1943.

[9] Kloskowski, T. Olkowska, J; Nazlica, A. Drewa, T. Acta. Pol. Pharm. Drug Res. 2010, 67,345 .

[10] Esmaeilzadeh, A.; Ebtekar, M.; Biglar, A.; Mohammad Hassan, Z. Afr. J. Microbiol. Res. 2012, 6, 4891.

[11] Aranha, O.; Wood Jr, D. P.; Sarkar, F. H.Clin. Cancer Res. 2000, 6, 891.

[12] Bourikas, L. A.; Kolios, G.; Valatas, V.; Notas, G.; Drygiannakis, I.; Pelagiadis, I.; Manousou, P.; Klironomos, S.; Mouzas, I. A.; Kouroumalis, E.Br. J. Pharmacol. 2009, 157,362 .

[13] Eidi Nita, M.; Nagawal, H.; Tominagal, O.; sunol, N. T.; Fujii, S.; Sasak, S.; Ful, C.G.; Takenouel, T.; Tsuruo, T.; Mutol, T. Br. J. Cancer. 1998, 78, 998.

[14] Hussy, P.; Maass, G.; Tummler, B.; Grosse, F.; Schomburg, U. Antimicrob. Agents. Chemother. 1986, 29, 1073.

[15] Korolyov, A.;Dorbes, S.; Azéma, J.; Guidetti, B.; Danel, M. Theys, D. L.; Gras, T.; Dubois, J.; Kiss, R.; Martino, R.; Martino, M. M.Bioorg. Med. Chem. 2010, 18, 8537.

[16] Al-Trawneh, S. A.; Zahra, J. A.; Kamal, M. R.; El-Abadelah, M. M.; Zani, F.; Incerti, M.; Cavazzoni, A.; Alfieri, R. R.; Petronini, P. G.; Vicini, P.Bioorg. Med. Chem. 2010, 18, 5873.

[17] Teicher, B. A. Biochem. Pharmacol. 2008, 75, 1262.

[18] Sanchez-Martin, R.; Campos, J. M.;Conejo-Garcia, A.; Cruz-Lopez, O.; Banez-Coronel, M.; Rodriguez-Gonzalez, A.; Gallo, M. A.; Lacal, J. C.; Espinosa, A.J. Med. Chem. 2005, 48, 3354.

[19] Robinson, M. J.; Martin, B. A.; Gootz, T. D.; Mcguirk, P. R.; Osheroff1, N. Antimicrob. Agents. chemother. 1992, 36, 751.

[20] Zeng, Q.; Kwok, Y.; Kerwin, S. M.; Mangold, G.; Hurley, L. H. J. Med. Chem. 1998, $41,4273$. 
[21] Clement, J. J.; Burros, N.; Jarvis, K.; Chu, D. T. W.; Swiniarski, J.; Alder, J. Cancer Res. 1995, 55, 830 .

[22] Aranha, O.; Grignon, R.; Fernandes, N.; McDonnell, T. J.; Wood, D. P.; Sarkar, F. H. Int. J. Oncol. 2003, 22, 787.

[23] Kloskowski, T.; Gurtowska, N.; Bajek, A.; Drewa, T.Med. Hypotheses. 2012, 78, 235.

[24] Synthesis of 1-cyclopropyl-6-fluoro-7-[4-(2-\{4-methylpiperazin-1-yl\}acetyl)piperazin-1yl]-4-oxo-1,4-dihydroquinoline-3-carboxylic acid (3a): To a solution of $N$ methylpiperazine $(0.9819 \mathrm{mmol})$ in dry DMF $(4 \mathrm{~mL})$, triethylamine $(0.27 \mathrm{~mL}, 1.9638$ mmol) and potassium iodide $(16.29 \mathrm{mg}, 0.0981 \mathrm{mmol})$ were added at RT under $\mathrm{N}_{2}$ atmosphere. To the resultant mixture, compound $2(0.4 \mathrm{~g}, 0.9819 \mathrm{mmol})$ was added and heated at $150^{\circ} \mathrm{C}$. After the reaction was complete, as indicated by TLC, DMF was evaporated in vacuo. The obtained residue was diluted with $20 \mathrm{~mL}$ of water. The compound was extracted with $\mathrm{CH}_{2} \mathrm{Cl}_{2}(3 \times 5 \mathrm{~mL})$. The organic layers were collected, washed with saturated brine solution, dried over anhydrous $\mathrm{MgSO}_{4}$ and concentrated in vacuo. The resultant crude was purified by column chromatography $\left[\mathrm{CH}_{2} \mathrm{Cl}_{2} / \mathrm{MeOH}\right.$ (1$10 \%)]$ to get the title compounds. m.p. $248-250{ }^{\circ} \mathrm{C} ;{ }^{1} \mathrm{H}$ NMR $\left(300 \mathrm{MHz}, \mathrm{DMSO}-\mathrm{D}_{6}\right) \delta$ $1.18(\mathrm{t}, 2 \mathrm{H}, J=7.2 \mathrm{~Hz}), 1.29(\mathrm{t}, 2 \mathrm{H}, J=6.9 \mathrm{~Hz}), 2.67(\mathrm{~m}, 4 \mathrm{H}), 2.89(\mathrm{~m}, 4 \mathrm{H}), 3.02$ (s, $3 \mathrm{H}), 3.16(\mathrm{~m}, 4 \mathrm{H}), 3.28(\mathrm{~m}, 2 \mathrm{H}), 3.76(\mathrm{~m}, 4 \mathrm{H}), 3.81(\mathrm{tt}, 1 \mathrm{H}, J=7.2 \mathrm{~Hz}, J=6.9 \mathrm{~Hz}), 7.52$ $\left(\mathrm{d}, 1 \mathrm{H}, J_{\mathrm{H}-\mathrm{F}}=7.5 \mathrm{~Hz}\right), 7.89\left(\mathrm{~d}, 1 \mathrm{H}, J_{\mathrm{H}-\mathrm{F}}=13.2 \mathrm{~Hz}\right), 8.63(\mathrm{~s}, 1 \mathrm{H}), 15.18(\mathrm{~s}, 1 \mathrm{H}) .{ }^{13} \mathrm{C} \mathrm{NMR}$ $\left(100.61 \mathrm{MHz}, \mathrm{CDCl}_{3}\right) \delta 176.82\left(\mathrm{~d}, J_{\mathrm{C}-\mathrm{F}}=2.2 \mathrm{~Hz}\right), 167.56,166.43,153.21\left(\mathrm{~d}, J_{\mathrm{C}-\mathrm{F}}=249.3\right.$ $\mathrm{Hz}), 147.23,145.12\left(\mathrm{~d}, J_{\mathrm{C}-\mathrm{F}}=10.3 \mathrm{~Hz}\right), 138.95,119.91\left(\mathrm{~d}, J_{\mathrm{C}-\mathrm{F}}=8.1 \mathrm{~Hz}\right), 111.97\left(\mathrm{~d}, J_{\mathrm{C}-\mathrm{F}}=\right.$ $24.14 \mathrm{~Hz}), 107.12,104.89$ (d, $\left.J_{\mathrm{C}-\mathrm{F}}=3.7 \mathrm{~Hz}\right), 53.67,51.12,50.89$, 49.16, 45.91, 41.39, 35.58, 8.12. ESI-MS (m/z): calcd. for $\mathrm{C}_{24} \mathrm{H}_{30} \mathrm{FN}_{5} \mathrm{O}_{4} 471.23$, found $472.39[\mathrm{M}+\mathrm{H}]^{+}$. 
<smiles>O=C(O)c1cn(C2CC2)c2cc(N3CCNCC3)c(F)cc2c1=O</smiles><smiles>O=C(O)c1cn(C2CC2)c2c(F)c(-c3ccc(O)cc3)c(F)cc2c1=O</smiles><smiles>O=C(O)c1cn(C2CC2)c2cc(-c3ccc(O)cc3)c(F)cc2c1=O</smiles><smiles></smiles><smiles>NC1CCN(c2c(F)cc3c(=O)c(C(=O)O)cn4c3c2Oc2ccccc2-4)C1</smiles>

Figure 1. Structures of somefluoroquinolone anticancer agents.

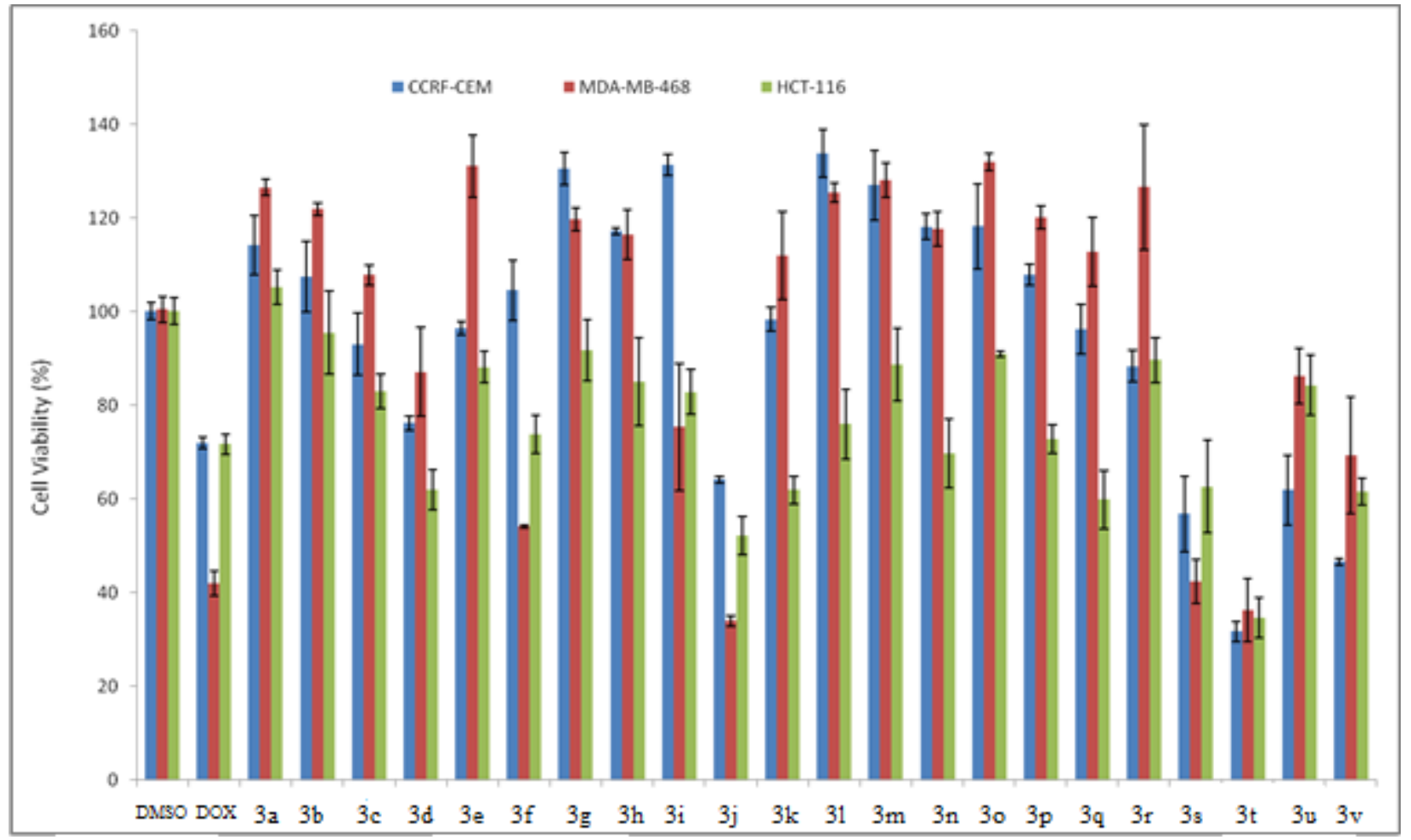

Figure 2: Antiproliferative activity of compound 3a-v

Scheme 1: Synthesis of ciprofloxacin derivatives (3a-v) 
<smiles>CCC(C)C</smiles>

1<smiles>O=C(O)c1cn(C2CC2)c2cc(N3CCN(C(=O)CCl)CC3)c(F)cc2c1=O</smiles>

2<smiles>[R]N1CCN(CC(=O)N2CCN(c3cc4c(cc3F)c(=O)c(C(=O)O)cn4C3CC3)CC2)CC1</smiles>

Reagents and conditions: (a) $\mathrm{Et}_{3} \mathrm{~N}, \mathrm{ClCH}_{2} \mathrm{COCl}_{2} \mathrm{CH}_{2} \mathrm{Cl}_{2}, \mathrm{O}^{\circ} \mathrm{C}-\mathrm{RT}$; (b) $\mathrm{Et}_{3} \mathrm{~N}, \mathrm{KI}$, substituted piperazines, $150^{\circ} \mathrm{C}$.

\section{Synthesis of novel ciprofloxacin analogues and evaluation of their anti-proliferative effect on human cancer cell lines}

NarvaSuresh $^{\mathrm{a}}$, HunsurNagendraNagesh ${ }^{\mathrm{a}}$, KondapalliVenkataGowri Chandra Sekhar ${ }^{\mathrm{a},{ }^{*}}$ Anil Kumar ${ }^{\mathrm{b}}$, Amir N. Shirazi ${ }^{\mathrm{c}}$, KeykavousParang ${ }^{\mathrm{ca}}$ Department of Chemistry, Birla Institute of Technology \& Science-Pilani, Hyderabad Campus, Jawahar Nagar, Hyderabad - 500 078, Andhra Pradesh, India. ${ }^{b}$ Department of Chemistry, Birla Institute of Technology \& Science, Pilani- 333031, Rajasthan, India ${ }^{\mathrm{c}}$ Department of Biomedical and Pharmaceutical Sciences, College of Pharmacy, University of Rhode Island, Kingston 02881 , USA

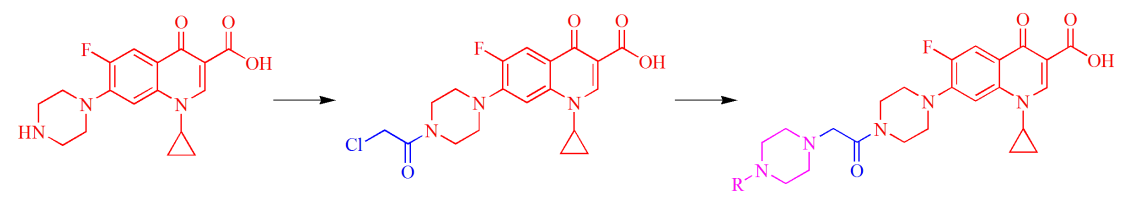




\section{Supplementary Data}

\section{Synthesis of novel ciprofloxacin analogues and evaluation of their anti-proliferative effect on human cancer cell lines}

NarvaSuresh $^{\mathrm{a}}$, HunsurNagendraNagesh ${ }^{\mathrm{a}}$, KondapalliVenkataGowri Chandra Sekhar ${ }^{\mathrm{a},{ }^{*}}$, Anil Kumar $^{\mathrm{b}}$, Amir N. Shirazi ${ }^{\mathrm{c}}$, KeykavousParang ${ }^{\mathrm{c}}$

${ }^{a}$ Department of Chemistry, Birla Institute of Technology \& Science-Pilani, Hyderabad Campus, Jawahar Nagar, Hyderabad - 500 078, Andhra Pradesh, India.

${ }^{\mathrm{b}}$ Department of Chemistry, Birla Institute of Technology \& Science, Pilani- 333031, Rajasthan, India

'Department of Biomedical and Pharmaceutical Sciences, College of Pharmacy, University of Rhode Island, Kingston 02881, USA

\section{*Corresponding author:}

K.V.G. Chandra SekharDepartment of Chemistry, Birla Institute of Technology and SciencePilani, Hyderabad, INDIA, PIN-500 078; Phone: +91-40-66303527; E-mail address::

kvgc@hyderabad.bits-pilani.ac.in, kvgcs@yahoo.com 
Table of Contents:

1. General 3

2. Cell Culture and Cell Proliferation Assay 3

3. Physical and Spectral Data for3a-3v 4 


\section{General:}

All reagents were purchased from commercial available sources and used without further purification. CP was purchased from Sigma Aldrich (>98\%). All reactions were monitored by analytical Thin Layer Chromatography (TLC) performed on E-Merck $0.25 \mathrm{~mm}$ pre coated silica gel glass plates (60 F254) using mixture of dichloromethane and methanol. Visualization of the spots on TLC plates was achieved either by exposure to UV light or by dipping the plates in ninhydrin solution and heating the plates at $120^{\circ} \mathrm{C}$. Column chromatography was performed using silica gel (Acme, 100-200mesh). Solvents were dried according to conventional methods and purified by distillation prior to use. Solvents for chromatography (dichloromethane and methanol) were distilled prior to use. Evaporations were carried out under reduced pressure on Buchi rotary evaporator below $40-45^{\circ} \mathrm{C}$. Melting points were obtained using Stuart SMP30 system and are uncorrected. Infrared (IR) spectra were recorded in $\mathrm{KBr}$ pellets on Schimadzu IR Prestige-21 FT-IR spectrophotometer $\left(\mathrm{cm}^{-1}\right) .{ }^{1} \mathrm{H}$ and ${ }^{13} \mathrm{C}$ NMR spectra were recorded on Avance 300 (300.132 MHz for ${ }^{1} \mathrm{H}, 100.61 \mathrm{MHz}$ for $\left.{ }^{13} \mathrm{C}\right)$, in $\mathrm{CDCl}_{3}$ or DMSO- $\mathrm{d}_{6}$. Chemical shifts have been expressed in parts per million $(\delta)$ relative to tetramethylsilane $(\delta=0.0)$ as an internal standard and coupling constants $(J)$ in Hertz. Low-resolution mass spectra (ESI-MS) were recorded on Shimadzu.

\section{Cell Culture and Cell Proliferation Assay:}

Cell Culture: Human caucasian acute lymphoblastic leukaemiacells (CCRF-CEM), breast adenocarcinoma (MDA-MB-468) and human colon carcinoma cells (HCT-116) were obtained from American type culture collection. Cells were grown on $75 \mathrm{~cm}^{2}$ cell culture flasks with EMEM (Eagle's minimum essential medium), supplemented with 10\% fetal bovine serum, and $1 \%$ penicillin/streptomycin solution $(10,000$ units of penicillin and $10 \mathrm{mg}$ of streptomycin in $0.9 \% \mathrm{NaCl}$ ) in a humidified atmosphere of $5 \% \mathrm{CO} 2,95 \%$ air at $37^{\circ} \mathrm{C}$.

Cell Proliferation Assay:Cell proliferation assay was carried out using CellTiter 96 aqueous one solution cell proliferation assay kit (Promega, USA). Briefly, upon reaching about 75-80\% confluency, 5000 cells/well were plated in 96-well microplate in 100 EL media. After seeding for $72 \mathrm{~h}$, the cells were treated with $50 \mu \mathrm{M}$ compound in triplicate. Doxorubicin $(10 \mu \mathrm{M})$ was used as the positive control. At the end of the sample exposure period (72 h), $20 \mu \mathrm{L}$ CellTiter 96 aqueous solution was added. The plate was returned to the incubator for $1 \mathrm{~h}$ in a humidified 
atmosphere at $37{ }^{\circ} \mathrm{C}$. The absorbance of the formazan product was measured at $490 \mathrm{~nm}$ using microplate reader. The blank control was recorded by measuring the absorbance at $490 \mathrm{~nm}$ with wells containing medium mixed with CellTiter 96 aqueous solution but no cells. Results were expressed as the percentage of the control (without compound set at 100\%).

\section{Physical and spectral data for $\mathbf{3 b - v}$}

7-[4-(2-\{4-(4-chlorophenyl)piperazin-1-yl\}acetyl)piperazin-1-yl]-1-cyclopropyl-6-fluoro-4-oxo-1,4-

dihydroquinoline-3-carboxylic acid (3b)

m.p. 249-250 ${ }^{\circ}$; ${ }^{1} \mathrm{H}$ NMR (300 MHz, DMSO-D 6 ) $\delta 1.18$ (t, 2H, J=7.2 Hz), 1.29 (t, 2H, J = 6.9

Hz), $2.67(\mathrm{~m}, 4 \mathrm{H}), 2.98(\mathrm{~m}, 4 \mathrm{H}), 3.26(\mathrm{~m}, 4 \mathrm{H}), 3.32(\mathrm{~m}, 2 \mathrm{H}), 3.67$ (m, 4H), 3.79 (tt, 1H, J = 7.2 $\mathrm{Hz}, J=6.9 \mathrm{~Hz}), 6.52(\mathrm{~d}, 2 \mathrm{H}, J=8.5 \mathrm{~Hz}), 7.1(\mathrm{~d}, 2 \mathrm{H}, J=5.8 \mathrm{~Hz}), 7.52\left(\mathrm{~d}, 1 \mathrm{H}, J_{\mathrm{H}-\mathrm{F}}=7.5 \mathrm{~Hz}\right)$, $7.89\left(\mathrm{~d}, 1 \mathrm{H}, J_{\mathrm{H}-\mathrm{F}}=13.2 \mathrm{~Hz}\right), 8.63(\mathrm{~s}, 1 \mathrm{H}), 15.18(\mathrm{~s}, 1 \mathrm{H}),{ }^{13} \mathrm{C} \mathrm{NMR}\left(100.61 \mathrm{MHz}, \mathrm{CDCl}_{3}\right) \delta$ $176.82\left(\mathrm{~d}, J_{\mathrm{C}-\mathrm{F}}=2.2 \mathrm{~Hz}\right), 167.56,166.43,153.21\left(\mathrm{~d}, J_{\mathrm{C}-\mathrm{F}}=249.3 \mathrm{~Hz}\right), 147.84,147.23,145.12(\mathrm{~d}$, $\left.J_{\mathrm{C}-\mathrm{F}}=10.3 \mathrm{~Hz}\right), 138.95,132.57,125.51,119.91\left(\mathrm{~d}, J_{\mathrm{C}-\mathrm{F}}=8.1 \mathrm{~Hz}\right), 116.38,111.97\left(\mathrm{~d}, J_{\mathrm{C}-\mathrm{F}}=\right.$ $24.14 \mathrm{~Hz}), 107.12,104.89$ (d, $\left.J_{\mathrm{C}-\mathrm{F}}=3.7 \mathrm{~Hz}\right), 53.89,51.12,50.46,49.12$, 45.84, 35.82, 8.43. ESIMS (m/z): calcd. for $\mathrm{C}_{29} \mathrm{H}_{31} \mathrm{ClFN}_{5} \mathrm{O}_{4}$ 567.20, found $568.29[\mathrm{M}+\mathrm{H}]^{+}$.

7-[4-(2-\{4-acetylpiperazin-1-yl\}acetyl)piperazin-1-yl]-1-cyclopropyl-6-fluoro-4-oxo-1,4-

dihydroquinoline-3-carboxylic acid (3c)

m.p. 230-231 ${ }^{\circ} \mathrm{C} ;{ }^{1} \mathrm{H}$ NMR (300 MHz, DMSO-D 6 ) $\delta 1.18$ (t, 2H, J=7.2 Hz), 1.29 (t, 2H, J = 6.9 Hz), $2.15(\mathrm{~s}, 3 \mathrm{H}), 2.52(\mathrm{~m}, 4 \mathrm{H}), 2.86(\mathrm{~m}, 4 \mathrm{H}), 3.21(\mathrm{~m}, 4 \mathrm{H}), 3.31(\mathrm{~m}, 2 \mathrm{H}), 3.76(\mathrm{~m}, 4 \mathrm{H}), 3.82(\mathrm{tt}$, $1 \mathrm{H}, J=7.2 \mathrm{~Hz}, J=6.9 \mathrm{~Hz}), 7.52\left(\mathrm{~d}, 1 \mathrm{H}, J_{\mathrm{H}-\mathrm{F}}=7.5 \mathrm{~Hz}\right), 7.89\left(\mathrm{~d}, 1 \mathrm{H}, J_{\mathrm{H}-\mathrm{F}}=13.2 \mathrm{~Hz}\right), 8.63(\mathrm{~s}$, $1 \mathrm{H}), 15.18(\mathrm{~s}, 1 \mathrm{H}) .{ }^{13} \mathrm{C}$ NMR $\left(100.61 \mathrm{MHz}, \mathrm{CDCl}_{3}\right) \delta 176.82\left(\mathrm{~d}, J_{\mathrm{C}-\mathrm{F}}=2.2 \mathrm{~Hz}\right), 168.39,167.56$, $153.21\left(\mathrm{~d}, J_{\mathrm{C}-\mathrm{F}}=249.3 \mathrm{~Hz}\right), 147.23,145.12\left(\mathrm{~d}, J_{\mathrm{C}-\mathrm{F}}=10.3 \mathrm{~Hz}\right), 138.95,119.91\left(\mathrm{~d}, J_{\mathrm{C}-\mathrm{F}}=8.1 \mathrm{~Hz}\right)$, $111.97\left(\mathrm{~d}, J_{\mathrm{C}-\mathrm{F}}=24.14 \mathrm{~Hz}\right), 107.12,104.89\left(\mathrm{~d}, J_{\mathrm{C}-\mathrm{F}}=3.7 \mathrm{~Hz}\right), 62.45,52.83,51.15,48.86,35.81$, 25.14, 8.17. ESI-MS (m/z): calcd. for $\mathrm{C}_{25} \mathrm{H}_{30} \mathrm{FN}_{5} \mathrm{O}_{5} 499.22$, found 500.42[M + H] $]^{+}$.

7-[4-(2-\{4-benzylpiperazin-1-yl\}acetyl)piperazin-1-yl]-1-cyclopropyl-6-fluoro-4-oxo-1,4dihydroquinoline-3-carboxylic acid $(3 \mathrm{~d})$ 
m.p. 104-106 ${ }^{\circ}$; ${ }^{1} \mathrm{H}$ NMR (300 MHz, DMSO-D $) \delta 1.18$ (t, 2H, J= 7.2 Hz), 1.29 (t, 2H, J = 6.9 Hz), $2.72(\mathrm{~m}, 4 \mathrm{H}), 2.93(\mathrm{~m}, 4 \mathrm{H}), 3.15(\mathrm{~s}, 2 \mathrm{H}), 3.32(\mathrm{~m}, 4 \mathrm{H}), 3.46(\mathrm{~m}, 2 \mathrm{H}), 3.62(\mathrm{~m}, 4 \mathrm{H}), 3.71$ (tt, $1 \mathrm{H}, J=7.2 \mathrm{~Hz}, J=6.9 \mathrm{~Hz}), 7.3(\mathrm{~m}, 5 \mathrm{H}), 7.52\left(\mathrm{~d}, 1 \mathrm{H}, J_{\mathrm{H}-\mathrm{F}}=7.5 \mathrm{~Hz}\right), 7.89\left(\mathrm{~d}, 1 \mathrm{H}, J_{\mathrm{H}-\mathrm{F}}=13.2\right.$ $\mathrm{Hz}), 8.63$ (s, 1H), $15.18(\mathrm{~s}, 1 \mathrm{H}) .{ }^{13} \mathrm{C} \mathrm{NMR}\left(100.61 \mathrm{MHz}, \mathrm{CDCl}_{3}\right) \delta 177.02\left(\mathrm{~d}, J_{\mathrm{C}-\mathrm{F}}=2.2 \mathrm{~Hz}\right)$, $168.33,153.6\left(\mathrm{~d}, J_{\mathrm{C}-\mathrm{F}}=249.3 \mathrm{~Hz}\right), 146.21,145.49\left(\mathrm{~d}, J_{\mathrm{C}-\mathrm{F}}=10.3 \mathrm{~Hz}\right), 139.01,127.12,126.75$, $126.13,120.15\left(\mathrm{~d}, J_{\mathrm{C}-\mathrm{F}}=8.1 \mathrm{~Hz}\right), 112.51\left(\mathrm{~d}, J_{\mathrm{C}-\mathrm{F}}=24.14 \mathrm{~Hz}\right), 108.16,105.08\left(\mathrm{~d}, J_{\mathrm{C}-\mathrm{F}}=3.7 \mathrm{~Hz}\right)$, 61.41, 54.31, 51.17, 51.48, 49.11, 45.07, 35.12, 8.65. ESI-MS (m/z): calcd. for $\mathrm{C}_{30} \mathrm{H}_{34} \mathrm{FN}_{5} \mathrm{O}_{4}$ 547.26, found $548.62[\mathrm{M}+\mathrm{H}]^{+}$.

1-cyclopropyl-6-fluoro-4-oxo-7-[4-(2-\{4-phenylpiperazin-1-yl\}acetyl)piperazin-1-yl]-1,4dihydroquinoline-3-carboxylic acid (3e) m.p. 212-214 ${ }^{\circ} \mathrm{C} ;{ }^{1} \mathrm{H}$ NMR (300 MHz, DMSO-D 6 ) $\delta 1.18$ (t, 2H, J=7.2 Hz), 1.29 (t, 2H, J = 6.9 Hz), $2.62(\mathrm{~m}, 4 \mathrm{H}), 2.91(\mathrm{~m}, 4 \mathrm{H}), 3.28(\mathrm{~m}, 4 \mathrm{H}), 3.44(\mathrm{~m}, 2 \mathrm{H}), 3.68(\mathrm{~m}, 4 \mathrm{H}), 3.81(\mathrm{tt}, 1 \mathrm{H}, J=7.2$ $\mathrm{Hz}, J=6.9 \mathrm{~Hz}), 7.23(\mathrm{~m}, 5 \mathrm{H}), 7.52\left(\mathrm{~d}, 1 \mathrm{H}, J_{\mathrm{H}-\mathrm{F}}=7.5 \mathrm{~Hz}\right), 7.89\left(\mathrm{~d}, 1 \mathrm{H}, J_{\mathrm{H}-\mathrm{F}}=13.2 \mathrm{~Hz}\right), 8.63(\mathrm{~s}$, $1 \mathrm{H}), 15.18(\mathrm{~s}, 1 \mathrm{H}) .{ }^{13} \mathrm{C}$ NMR $\left(100.61 \mathrm{MHz}, \mathrm{CDCl}_{3}\right) \delta 177.02\left(\mathrm{~d}, J_{\mathrm{C}-\mathrm{F}}=2.2 \mathrm{~Hz}\right), 168.33,166.82$, $153.6\left(\mathrm{~d}, J_{\mathrm{C}-\mathrm{F}}=249.3 \mathrm{~Hz}\right), 147.53,145.49\left(\mathrm{~d}, J_{\mathrm{C}-\mathrm{F}}=10.3 \mathrm{~Hz}\right), 144.21,139.01,130.09,128.41$, $127.74,120.15\left(\mathrm{~d}, J_{\mathrm{C}-\mathrm{F}}=8.1 \mathrm{~Hz}\right), 112.51\left(\mathrm{~d}, J_{\mathrm{C}-\mathrm{F}}=24.14 \mathrm{~Hz}\right), 108.16,105.08\left(\mathrm{~d}, J_{\mathrm{C}-\mathrm{F}}=3.7 \mathrm{~Hz}\right)$, 54.65, 52.42, 51.17, 49.33, 45.40, 34.86, 8.18. ESI-MS (m/z): calcd. for $\mathrm{C}_{29} \mathrm{H}_{32} \mathrm{FN}_{5} \mathrm{O}_{4} 533.24$, found $534.31[\mathrm{M}+\mathrm{H}]^{+}$.

7-[4-(2-\{4-(2-chlorophenyl)piperazin-1-yl\}acetyl)piperazin-1-yl]-1-cyclopropyl-6-fluoro-4-oxo-1,4dihydroquinoline-3-carboxylic acid (3f) m.p. 138-139 ${ }^{\circ} \mathrm{C} ;{ }^{1} \mathrm{H}$ NMR (300 MHz, DMSO-D $) ~ \delta 1.18(\mathrm{t}, 2 \mathrm{H}, J=7.2 \mathrm{~Hz}), 1.29$ (t, 2H, $J=6.9$ Hz), 2.56 (m, 4H), $2.82(\mathrm{~m}, 4 \mathrm{H}), 3.18(\mathrm{~m}, 4 \mathrm{H}), 3.37$ (m, 2H), $3.72(\mathrm{~m}, 4 \mathrm{H}), 3.76$ (tt, 1H, J = 7.2 $\mathrm{Hz}, J=6.9 \mathrm{~Hz}), 7.05(\mathrm{t}, 1 \mathrm{H}), 7.13(\mathrm{~d}, 1 \mathrm{H}), 7.55(\mathrm{~m}, 2 \mathrm{H}), 7.52\left(\mathrm{~d}, 1 \mathrm{H}, J_{\mathrm{H}-\mathrm{F}}=7.5 \mathrm{~Hz}\right), 7.89(\mathrm{~d}, 1 \mathrm{H}$, $\left.J_{\mathrm{H}-\mathrm{F}}=13.2 \mathrm{~Hz}\right), 8.63(\mathrm{~s}, 1 \mathrm{H}), 15.18(\mathrm{~s}, 1 \mathrm{H}) .{ }^{13} \mathrm{C} \mathrm{NMR}\left(100.61 \mathrm{MHz}, \mathrm{CDCl}_{3}\right) \delta 177.02\left(\mathrm{~d}, J_{\mathrm{C}-\mathrm{F}}=\right.$ $2.2 \mathrm{~Hz}), 168.33,166.82,153.6\left(\mathrm{~d}, J_{\mathrm{C}-\mathrm{F}}=249.3 \mathrm{~Hz}\right), 147.53,145.49\left(\mathrm{~d}, J_{\mathrm{C}-\mathrm{F}}=10.3 \mathrm{~Hz}\right), 143.84$, $139.01,130.95,129.13,128.64,124.2,122.26,120.15\left(\mathrm{~d}, J_{\mathrm{C}-\mathrm{F}}=8.1 \mathrm{~Hz}\right), 112.51\left(\mathrm{~d}, J_{\mathrm{C}-\mathrm{F}}=24.14\right.$ $\mathrm{Hz}), 108.16,105.08\left(\mathrm{~d}, J_{\mathrm{C}-\mathrm{F}}=3.7 \mathrm{~Hz}\right), 53.11,51.75,50.83$, 48.96, 44.72, 35.42, 7.87. ESI-MS (m/z): calcd. for $\mathrm{C}_{29} \mathrm{H}_{31} \mathrm{ClFN}_{5} \mathrm{O}_{4}$ 567.20, found $568.35[\mathrm{M}+\mathrm{H}]^{+}$. 
7-[4-(2-\{4-(4-cyanophenyl)piperazin-1-yl\}acetyl)piperazin-1-yl]-1-cyclopropyl-6-fluoro-4-oxo-1,4dihydroquinoline-3-carboxylic acid (3g)

m.p. 278-279 ${ }^{\circ}$; ${ }^{1} \mathrm{H}$ NMR (300 MHz, DMSO-D 6 ) $\delta 1.18$ (t, 2H, $J=7.2 \mathrm{~Hz}$ ), 1.29 (t, 2H, $J=6.9$ $\mathrm{Hz}), 2.45(\mathrm{~m}, 4 \mathrm{H}), 2.79(\mathrm{~m}, 4 \mathrm{H}), 3.21(\mathrm{~m}, 4 \mathrm{H}), 3.32(\mathrm{~m}, 2 \mathrm{H}), 3.67(\mathrm{~m}, 4 \mathrm{H}), 3.71(\mathrm{tt}, 1 \mathrm{H}, J=7.2$ $\mathrm{Hz}, J=6.9 \mathrm{~Hz}), 6.65(\mathrm{~d}, 2 \mathrm{H}, J=8.5 \mathrm{~Hz}), 7.3(\mathrm{~d}, 2 \mathrm{H}, J=5.8 \mathrm{~Hz}), 7.52\left(\mathrm{~d}, 1 \mathrm{H}, J_{\mathrm{H}-\mathrm{F}}=7.5 \mathrm{~Hz}\right)$, $7.89\left(\mathrm{~d}, 1 \mathrm{H}, J_{\mathrm{H}-\mathrm{F}}=13.2 \mathrm{~Hz}\right), 8.63(\mathrm{~s}, 1 \mathrm{H}), 15.18(\mathrm{~s}, 1 \mathrm{H}) .{ }^{13} \mathrm{C}$ NMR $\left(100.61 \mathrm{MHz}, \mathrm{CDCl}_{3}\right) \delta$ $176.82\left(\mathrm{~d}, J_{\mathrm{C}-\mathrm{F}}=2.2 \mathrm{~Hz}\right), 167.56,166.43,153.21\left(\mathrm{~d}, J_{\mathrm{C}-\mathrm{F}}=249.3 \mathrm{~Hz}\right), 147.84,147.23,145.12(\mathrm{~d}$, $\left.J_{\mathrm{C}-\mathrm{F}}=10.3 \mathrm{~Hz}\right), 138.95,131.86,126.93,119.91\left(\mathrm{~d}, J_{\mathrm{C}-\mathrm{F}}=8.1 \mathrm{~Hz}\right), 117.12,116.91,111.97\left(\mathrm{~d}, J_{\mathrm{C}-\mathrm{F}}\right.$ $=24.14 \mathrm{~Hz}), 107.12,104.89\left(\mathrm{~d}, J_{\mathrm{C}-\mathrm{F}}=3.7 \mathrm{~Hz}\right), 53.43,51.75,50.22,49.72,45.89,35.23,7.13$. ESI-MS (m/z): calcd. for $\mathrm{C}_{30} \mathrm{H}_{31} \mathrm{FN}_{6} \mathrm{O}_{4} 558.24$, found $559.38[\mathrm{M}+\mathrm{H}]^{+}$.

1-cyclopropyl-6-fluoro-7-[4-(2-\{4-(4-nitrophenyl)piperazin-1-yl\}acetyl)piperazin-1-yl]-4-oxo-1,4dihydroquinoline-3-carboxylic acid (3h)

m.p. $242-244^{\circ} \mathrm{C} ;{ }^{1} \mathrm{H}$ NMR (300 MHz, DMSO-D $) ~ \delta 1.18(\mathrm{t}, 2 \mathrm{H}, J=7.2 \mathrm{~Hz}), 1.29$ (t, $2 \mathrm{H}, J=6.9$ Hz), $2.54(\mathrm{~m}, 4 \mathrm{H}), 2.83$ (m, 4H), $3.23(\mathrm{~m}, 4 \mathrm{H}), 3.38(\mathrm{~m}, 2 \mathrm{H}), 3.69$ (m, 4H), 3.79 (tt, 1H, $J=7.2$ $\mathrm{Hz}, J=6.9 \mathrm{~Hz}), 6.7(\mathrm{~d}, 2 \mathrm{H}, J=8.5 \mathrm{~Hz}), 7.9(\mathrm{~d}, 2 \mathrm{H}, J=5.8 \mathrm{~Hz}), 7.52\left(\mathrm{~d}, 1 \mathrm{H}, J_{\mathrm{H}-\mathrm{F}}=7.5 \mathrm{~Hz}\right), 7.89$ $\left(\mathrm{d}, 1 \mathrm{H}, J_{\mathrm{H}-\mathrm{F}}=13.2 \mathrm{~Hz}\right), 8.63(\mathrm{~s}, 1 \mathrm{H}), 15.18(\mathrm{~s}, 1 \mathrm{H}) \cdot{ }^{13} \mathrm{C} \mathrm{NMR}\left(\mathrm{CDCl}_{3}, 100 \mathrm{MHz}\right) \delta 176.82\left(\mathrm{~d}, J_{\mathrm{C}-\mathrm{F}}\right.$ $=2.2 \mathrm{~Hz}), 167.56,166.43,153.21\left(\mathrm{~d}, J_{\mathrm{C}-\mathrm{F}}=249.3 \mathrm{~Hz}\right), 148.42,146.93,145.12\left(\mathrm{~d}, J_{\mathrm{C}-\mathrm{F}}=10.3\right.$ $\mathrm{Hz}), 138.95,132.45,128.41,119.91\left(\mathrm{~d}, J_{\mathrm{C}-\mathrm{F}}=8.1 \mathrm{~Hz}\right), 117.12,116.91,111.97\left(\mathrm{~d}, J_{\mathrm{C}-\mathrm{F}}=24.14\right.$ $\mathrm{Hz}), 107.12,104.89\left(\mathrm{~d}, J_{\mathrm{C}-\mathrm{F}}=3.7 \mathrm{~Hz}\right), 53.39,51.52,50.79,49.23,35.85,8.34$. ESI-MS $(\mathrm{m} / \mathrm{z})$ :calcd. for $\mathrm{C}_{29} \mathrm{H}_{31} \mathrm{FN}_{6} \mathrm{O}_{6} 578.23$, found $579.32[\mathrm{M}+\mathrm{H}]^{+}$.

1-cyclopropyl-6-fluoro-7-[4-(2-\{4-(3-methoxyphenyl)piperazin-1-yl\}acetyl)piperazin-1-yl]-4-oxo1,4-dihydroquinoline-3-carboxylicacid (3i) m.p. $144-145^{\circ} \mathrm{C} ;{ }^{1} \mathrm{H}$ NMR (300 MHz, DMSO-D $\left.{ }_{6}\right) \delta 1.18$ (t, 2H, $J=7.2 \mathrm{~Hz}$ ), 1.29 (t, 2H, $J=6.9$ Hz), $2.41(\mathrm{~m}, 4 \mathrm{H}), 2.72(\mathrm{~m}, 4 \mathrm{H}), 3.14(\mathrm{~m}, 4 \mathrm{H}), 3.46(\mathrm{~m}, 2 \mathrm{H}), 3.69$ (m, 4H), $3.76(\mathrm{~s}, 3 \mathrm{H}), 3.79$ (tt, $1 \mathrm{H}, J=7.2 \mathrm{~Hz}, J=6.9 \mathrm{~Hz}), 6.42(\mathrm{~d}, 1 \mathrm{H}), 6.5(\mathrm{~s}, 1 \mathrm{H}), 6.57(\mathrm{~d}, 1 \mathrm{H}), 7.15(\mathrm{t}, 1 \mathrm{H}), 7.52\left(\mathrm{~d}, 1 \mathrm{H}, J_{\mathrm{H}-\mathrm{F}}\right.$ $=7.5 \mathrm{~Hz}), 7.89\left(\mathrm{~d}, 1 \mathrm{H}, J_{\mathrm{H}-\mathrm{F}}=13.2 \mathrm{~Hz}\right), 8.63(\mathrm{~s}, 1 \mathrm{H}), 15.18(\mathrm{~s}, 1 \mathrm{H}) \cdot{ }^{13} \mathrm{C} \mathrm{NMR}\left(\mathrm{CDCl}_{3}, 100 \mathrm{MHz}\right)$ $\delta 177.02\left(\mathrm{~d}, J_{\mathrm{C}-\mathrm{F}}=2.2 \mathrm{~Hz}\right), 168.33,166.82,153.6\left(\mathrm{~d}, J_{\mathrm{C}-\mathrm{F}}=249.3 \mathrm{~Hz}\right), 146.27,145.49\left(\mathrm{~d}, J_{\mathrm{C}-\mathrm{F}}=\right.$ $10.3 \mathrm{~Hz}), 144.56,139.01,131.29,129.72,129.13,123.18,120.15\left(\mathrm{~d}, J_{\mathrm{C}-\mathrm{F}}=8.1 \mathrm{~Hz}\right), 112.51(\mathrm{~d}$, 
$\left.J_{\mathrm{C}-\mathrm{F}}=24.14 \mathrm{~Hz}\right), 110.3,108.16,105.08\left(\mathrm{~d}, J_{\mathrm{C}-\mathrm{F}}=3.7 \mathrm{~Hz}\right), 53.85,52.11,51.73,48.17,46.14$, 44.72, 35.42, 8.18. ESI-MS (m/z):calcd. for $\mathrm{C}_{30} \mathrm{H}_{34} \mathrm{FN}_{5} \mathrm{O}_{5} 563.25$, found $564.42[\mathrm{M}+\mathrm{H}]^{+}$.

7-[4-(2-\{4-benzhydrylpiperazin-1-yl\}acetyl)piperazin-1-yl]-1-cyclopropyl-6-fluoro-4-oxo-1,4-

dihydroquinoline-3-carboxylic acid (3j)

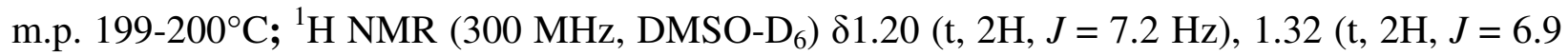
Hz), $2.43(\mathrm{~m}, 4 \mathrm{H}), 2.68(\mathrm{~m}, 4 \mathrm{H}), 2.96(\mathrm{~s}, 3 \mathrm{H}), 3.18(\mathrm{~m}, 4 \mathrm{H}), 3.48(\mathrm{~m}, 2 \mathrm{H}), 3.72(\mathrm{~m}, 4 \mathrm{H}), 3.83(\mathrm{tt}$, $1 \mathrm{H}, J=7.2 \mathrm{~Hz}, J=6.9 \mathrm{~Hz}), 4.12(\mathrm{~s}, 1 \mathrm{H}), 7.25(\mathrm{~m}, 10 \mathrm{H}), 7.52\left(\mathrm{~d}, 1 \mathrm{H}, J_{\mathrm{H}-\mathrm{F}}=7.5 \mathrm{~Hz}\right), 7.89(\mathrm{~d}, 1 \mathrm{H}$, $\left.J_{\mathrm{H}-\mathrm{F}}=13.2 \mathrm{~Hz}\right), 8.63(\mathrm{~s}, 1 \mathrm{H}), 15.18(\mathrm{~s}, 1 \mathrm{H}) .{ }^{13} \mathrm{C} \mathrm{NMR}\left(100.61 \mathrm{MHz}, \mathrm{CDCl}_{3}\right) \delta 177.02\left(\mathrm{~d}, J_{\mathrm{C}-\mathrm{F}}=\right.$ $2.2 \mathrm{~Hz}), 168.33,166.82,153.6\left(\mathrm{~d}, J_{\mathrm{C}-\mathrm{F}}=249.3 \mathrm{~Hz}\right), 147.53,145.49\left(\mathrm{~d}, J_{\mathrm{C}-\mathrm{F}}=10.3 \mathrm{~Hz}\right), 142.60$, 139.01, 128.52, 127.86, 127.00, $120.15\left(\mathrm{~d}, J_{\mathrm{C}-\mathrm{F}}=8.1 \mathrm{~Hz}\right), 112.51\left(\mathrm{~d}, J_{\mathrm{C}-\mathrm{F}}=24.14 \mathrm{~Hz}\right), 108.16$, $105.08\left(\mathrm{~d}, J_{\mathrm{C}-\mathrm{F}}=3.7 \mathrm{~Hz}\right), 76.27,53.35,51.92,50.65,49.45,45.48,35.33,8.26$. ESI-MS $(\mathrm{m} / z)$ :calcd. for $\mathrm{C}_{36} \mathrm{H}_{38} \mathrm{FN}_{5} \mathrm{O}_{4} 623.29$, found $624.41[\mathrm{M}+\mathrm{H}]^{+}$.

1-cyclopropyl-6-fluoro-4-oxo-7-[4-(2-\{4-m-tolylpiperazin-1-yl\}acetyl)piperazin-1-yl]-1,4-

dihydroquinoline-3-carboxylicacid $(3 \mathbf{k})$

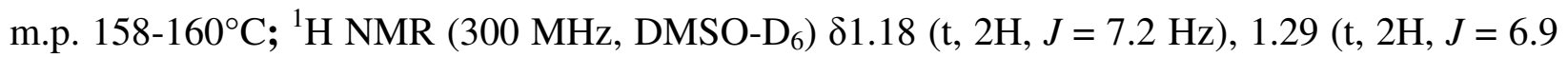
Hz), 2.19 (s, 3H), $2.38(\mathrm{~m}, 4 \mathrm{H}), 2.66(\mathrm{~m}, 4 \mathrm{H}), 3.38(\mathrm{~m}, 4 \mathrm{H}), 3.41(\mathrm{~m}, 2 \mathrm{H}), 3.72(\mathrm{~m}, 4 \mathrm{H}), 3.76(\mathrm{tt}$, $1 \mathrm{H}, J=7.2 \mathrm{~Hz}, J=6.9 \mathrm{~Hz}), 6.55(\mathrm{~d}, 1 \mathrm{H}), 6.68(\mathrm{~d}, 1 \mathrm{H}), 6.71(\mathrm{~s}, 1 \mathrm{H}), 7.04(\mathrm{t}, 1 \mathrm{H}), 7.52\left(\mathrm{~d}, 1 \mathrm{H}, J_{\mathrm{H}-}\right.$ $\mathrm{F}=7.5 \mathrm{~Hz}), 7.89\left(\mathrm{~d}, 1 \mathrm{H}, J_{\mathrm{H}-\mathrm{F}}=13.2 \mathrm{~Hz}\right), 8.63(\mathrm{~s}, 1 \mathrm{H}), 15.18(\mathrm{~s}, 1 \mathrm{H}) .{ }^{13} \mathrm{C} \mathrm{NMR}(100.61 \mathrm{MHz}$, $\left.\mathrm{CDCl}_{3}\right) \delta 177.02\left(\mathrm{~d}, J_{\mathrm{C}-\mathrm{F}}=2.2 \mathrm{~Hz}\right), 168.33,166.82,153.6\left(\mathrm{~d}, J_{\mathrm{C}-\mathrm{F}}=249.3 \mathrm{~Hz}\right), 146.03,145.49$ $\left(\mathrm{d}, J_{\mathrm{C}-\mathrm{F}}=10.3 \mathrm{~Hz}\right), 141.48,139.01,129.5,127.59,127.11,126.58,122.34,120.15\left(\mathrm{~d}, J_{\mathrm{C}-\mathrm{F}}=8.1\right.$ $\mathrm{Hz}), 112.51\left(\mathrm{~d}, J_{\mathrm{C}-\mathrm{F}}=24.14 \mathrm{~Hz}\right), 108.16,105.08\left(\mathrm{~d}, J_{\mathrm{C}-\mathrm{F}}=3.7 \mathrm{~Hz}\right), 53.87,51.12,50.86,49.43$, 45.12, 35.39, 22.29, 8.18. ESI-MS (m/z):calcd. for $\mathrm{C}_{30} \mathrm{H}_{34} \mathrm{FN}_{5} \mathrm{O}_{4} 547.26$, found $548.39[\mathrm{M}+\mathrm{H}]^{+}$.

1-cyclopropyl-6-fluoro-4-oxo-7-[4-(2-\{4-(1-phenylethyl)piperazin-1-yl\}acetyl)piperazin-1-yl]-1,4dihydroquinoline-3-carboxylicacid (3l) m.p. 212-214 ${ }^{\circ} \mathrm{C} ;{ }^{1} \mathrm{H}$ NMR (300 MHz, DMSO-D 6$) \delta 1.18$ (t, 2H, J=7.2 Hz), 1.20 (d, 3H), 1.29 (t, $2 \mathrm{H}, J=6.9 \mathrm{~Hz}), 2.39(\mathrm{~m}, 4 \mathrm{H}), 2.52(\mathrm{~m}, 4 \mathrm{H}), 3.06(\mathrm{q}, 1 \mathrm{H}), 3.31(\mathrm{~m}, 4 \mathrm{H}), 3.38(\mathrm{~m}, 2 \mathrm{H}), 3.64(\mathrm{~m}$, 4H), $3.78(\mathrm{tt}, 1 \mathrm{H}, J=7.2 \mathrm{~Hz}, J=6.9 \mathrm{~Hz}), 7.3(\mathrm{~m}, 5 \mathrm{H}), 7.52\left(\mathrm{~d}, 1 \mathrm{H}, J_{\mathrm{H}-\mathrm{F}}=7.5 \mathrm{~Hz}\right), 7.89(\mathrm{~d}, 1 \mathrm{H}$, $\left.J_{\mathrm{H}-\mathrm{F}}=13.2 \mathrm{~Hz}\right), 8.63(\mathrm{~s}, 1 \mathrm{H}), 15.18(\mathrm{~s}, 1 \mathrm{H}) .{ }^{13} \mathrm{C} \mathrm{NMR}\left(100.61 \mathrm{MHz}, \mathrm{CDCl}_{3}\right) \delta 177.02\left(\mathrm{~d}, J_{\mathrm{C}-\mathrm{F}}=\right.$ 
$2.2 \mathrm{~Hz}), 168.33,166.82,153.6\left(\mathrm{~d}, J_{\mathrm{C}-\mathrm{F}}=249.3 \mathrm{~Hz}\right), 147.53,145.49\left(\mathrm{~d}, J_{\mathrm{C}-\mathrm{F}}=10.3 \mathrm{~Hz}\right), 142.60$, $139.01,128.52,127.86,127.00,120.15\left(\mathrm{~d}, J_{\mathrm{C}-\mathrm{F}}=8.1 \mathrm{~Hz}\right), 112.51\left(\mathrm{~d}, J_{\mathrm{C}-\mathrm{F}}=24.14 \mathrm{~Hz}\right), 108.16$, $105.08\left(\mathrm{~d}, J_{\mathrm{C}-\mathrm{F}}=3.7 \mathrm{~Hz}\right), 72.21,54.11,52.19,51.07,48.69,46.18,34.04,22.67,8.13$. ESI-MS $(\mathrm{m} / z)$ :calcd. for $\mathrm{C}_{31} \mathrm{H}_{36} \mathrm{FN}_{5} \mathrm{O}_{4} 561.28$, found $562.41[\mathrm{M}+\mathrm{H}]^{+}$.

1-cyclopropyl-7-[4-(2-\{4-ethylpiperazin-1-yl\}acetyl)piperazin-1-yl]-6-fluoro-4-oxo-1,4dihydroquinoline-3-carboxylicacid ( $3 \mathbf{m})$ m.p. 239-240 ${ }^{\circ}$; ${ }^{1} \mathrm{H}$ NMR (300 MHz, DMSO-D 6 ) $\delta 1.08$ (t, 3H), 1.18 (t, 2H, $\left.J=7.2 \mathrm{~Hz}\right), 1.29$ (t, $2 \mathrm{H}, J=6.9 \mathrm{~Hz}), 2.9(\mathrm{q}, 2 \mathrm{H}), 2.36(\mathrm{~m}, 4 \mathrm{H}), 2.48(\mathrm{~m}, 4 \mathrm{H}), 3.32(\mathrm{~m}, 4 \mathrm{H}), 3.52(\mathrm{~m}, 2 \mathrm{H}), 3.67(\mathrm{~m}$, $4 \mathrm{H}), 3.79(\mathrm{tt}, 1 \mathrm{H}, J=7.2 \mathrm{~Hz}, J=6.9 \mathrm{~Hz}), 7.55\left(\mathrm{~d}, 1 \mathrm{H}, J_{\mathrm{H}-\mathrm{F}}=7.5 \mathrm{~Hz}\right), 7.89\left(\mathrm{~d}, 1 \mathrm{H}, J_{\mathrm{H}-\mathrm{F}}=13.2\right.$ $\mathrm{Hz}), 8.63(\mathrm{~s}, 1 \mathrm{H}), 15.18(\mathrm{~s}, 1 \mathrm{H}){ }^{13} \mathrm{C}$ NMR $\left(100.61 \mathrm{MHz}, \mathrm{CDCl}_{3}\right) \delta 176.82\left(\mathrm{~d}, J_{\mathrm{C}-\mathrm{F}}=2.2 \mathrm{~Hz}\right)$, 167.56, 166.43, $153.21\left(\mathrm{~d}, J_{\mathrm{C}-\mathrm{F}}=249.3 \mathrm{~Hz}\right), 147.23,145.12\left(\mathrm{~d}, J_{\mathrm{C}-\mathrm{F}}=10.3 \mathrm{~Hz}\right), 138.95,119.91$ $\left(\mathrm{d}, J_{\mathrm{C}-\mathrm{F}}=8.1 \mathrm{~Hz}\right), 111.97\left(\mathrm{~d}, J_{\mathrm{C}-\mathrm{F}}=24.14 \mathrm{~Hz}\right), 107.12,104.89\left(\mathrm{~d}, J_{\mathrm{C}-\mathrm{F}}=3.7 \mathrm{~Hz}\right), 54.56,52.23$, 51.67, 49.71, 48.87, 44.76, 34.74, 14.87, 8.45. ESI-MS (m/z):calcd. for $\mathrm{C}_{25} \mathrm{H}_{32} \mathrm{FN}_{5} \mathrm{O}_{4} 485.24$, found $486.37[\mathrm{M}+\mathrm{H}]^{+}$.

7-[4-(2-\{4-(2-cyanophenyl)piperazin-1-yl\}acetyl)piperazin-1-yl]-1-cyclopropyl-6-fluoro-4-oxo-1,4dihydroquinoline-3-carboxylic acid (3n) m.p. $222-223^{\circ} \mathrm{C}$; ${ }^{1} \mathrm{H}$ NMR (300 MHz, DMSO-D 6 ) $\delta 1.18$ (t, 2H, $J=7.2 \mathrm{~Hz}$ ), 1.29 (t, 2H, $J=6.9$ Hz), $2.62(\mathrm{~m}, 4 \mathrm{H}), 3.14(\mathrm{~m}, 4 \mathrm{H}), 3.34(\mathrm{~m}, 4 \mathrm{H}), 3.66(\mathrm{~m}, 2 \mathrm{H}), 3.77(\mathrm{~m}, 4 \mathrm{H}), 3.82(\mathrm{tt}, 1 \mathrm{H}, J=7.2$ $\mathrm{Hz}, J=6.9 \mathrm{~Hz}), 7.05(\mathrm{t}, 1 \mathrm{H}), 7.13(\mathrm{~d}, 1 \mathrm{H}), 7.55(\mathrm{~m}, 2 \mathrm{H}), 7.66\left(\mathrm{~d}, 1 \mathrm{H}, J_{\mathrm{H}-\mathrm{F}}=7.5 \mathrm{~Hz}\right), 7.92(\mathrm{~d}, 1 \mathrm{H}$, $\left.J_{\mathrm{H}-\mathrm{F}}=13.2 \mathrm{~Hz}\right), 8.63(\mathrm{~s}, 1 \mathrm{H}), 15.18(\mathrm{~s}, 1 \mathrm{H}) .{ }^{13} \mathrm{C} \mathrm{NMR}\left(100.61 \mathrm{MHz}, \mathrm{CDCl}_{3}\right) \delta 176.82\left(\mathrm{~d}, J_{\mathrm{C}-\mathrm{F}}=\right.$ $2.2 \mathrm{~Hz}), 167.56,166.43,153.21\left(\mathrm{~d}, J_{\mathrm{C}-\mathrm{F}}=249.3 \mathrm{~Hz}\right), 147.23,145.12\left(\mathrm{~d}, J_{\mathrm{C}-\mathrm{F}}=10.3 \mathrm{~Hz}\right), 142.43$, $138.95,128.2,127.43,126.32,122.78,119.91\left(\mathrm{~d}, J_{\mathrm{C}-\mathrm{F}}=8.1 \mathrm{~Hz}\right), 111.97\left(\mathrm{~d}, J_{\mathrm{C}-\mathrm{F}}=24.14 \mathrm{~Hz}\right)$, 108.23, 107.12, 104.89 (d, $\left.J_{\mathrm{C}-\mathrm{F}}=3.7 \mathrm{~Hz}\right), 81.42,53.59,51.12,50.58,49.33,45.06,35.99,8.54$. ESI-MS $(\mathrm{m} / \mathrm{z})$ :calcd. for $\mathrm{C}_{30} \mathrm{H}_{31} \mathrm{FN}_{6} \mathrm{O}_{4} 558.24$, found $559.36[\mathrm{M}+\mathrm{H}]^{+}$.

1-cyclopropyl-6-fluoro-4-oxo-7-[4-(2- \{4-(pyridine-2-yl)piperazin-1-yl\}acetyl) piperazin-1-yl]- 1,4dihydroquinoline-3-carboxylic acid (3o) 
m.p. 204-205 ${ }^{\circ} \mathrm{C}$; ${ }^{1} \mathrm{H}$ NMR (300 MHz, DMSO-D $) \delta 1.18(\mathrm{t}, 2 \mathrm{H}, J=7.2 \mathrm{~Hz}), 1.29(\mathrm{t}, 2 \mathrm{H}, J=6.9$ $\mathrm{Hz}), 2.57(\mathrm{~m}, 4 \mathrm{H}), 3.23(\mathrm{~m}, 4 \mathrm{H}), 3.31(\mathrm{~m}, 4 \mathrm{H}), 3.56(\mathrm{~m}, 2 \mathrm{H}), 3.61(\mathrm{~m}, 4 \mathrm{H}), 3.77(\mathrm{tt}, 1 \mathrm{H}, J=7.2$ $\mathrm{Hz}, J=6.9 \mathrm{~Hz}), 7.16(\mathrm{t}, 1 \mathrm{H}), 7.21(\mathrm{~d}, 1 \mathrm{H}), 7.62(\mathrm{~m}, 2 \mathrm{H}), 7.66\left(\mathrm{~d}, 1 \mathrm{H}, J_{\mathrm{H}-\mathrm{F}}=7.5 \mathrm{~Hz}\right), 7.92(\mathrm{~d}, 1 \mathrm{H}$, $\left.J_{\mathrm{H}-\mathrm{F}}=13.2 \mathrm{~Hz}\right), 8.63(\mathrm{~s}, 1 \mathrm{H}), 15.18(\mathrm{~s}, 1 \mathrm{H}) .{ }^{13} \mathrm{C} \mathrm{NMR}\left(100.61 \mathrm{MHz}, \mathrm{CDCl}_{3}\right) \delta 176.82\left(\mathrm{~d}, J_{\mathrm{C}-\mathrm{F}}=\right.$ $2.2 \mathrm{~Hz}), 167.56,166.43,154.34,153.21\left(\mathrm{~d}, J_{\mathrm{C}-\mathrm{F}}=249.3 \mathrm{~Hz}\right), 150.78,148.43,147.23,146.07$, $145.12\left(\mathrm{~d}, J_{\mathrm{C}-\mathrm{F}}=10.3 \mathrm{~Hz}\right), 138.95,121.56,119.91\left(\mathrm{~d}, J_{\mathrm{C}-\mathrm{F}}=8.1 \mathrm{~Hz}\right), 111.97\left(\mathrm{~d}, J_{\mathrm{C}-\mathrm{F}}=24.14 \mathrm{~Hz}\right)$, 107.12, $104.89\left(\mathrm{~d}, J_{\mathrm{C}-\mathrm{F}}=3.7 \mathrm{~Hz}\right), 53.78,53.12,50.96,48.76,45.78,37.23,8.45$. ESI-MS $(\mathrm{m} / \mathrm{z})$ :calcd. for $\mathrm{C}_{28} \mathrm{H}_{31} \mathrm{FN}_{6} \mathrm{O}_{4} 534.24$, found $535.36[\mathrm{M}+\mathrm{H}]^{+}$.

1-cyclopropyl-6-fluoro-4-oxo-7-[4-(2-\{4-(pyrimidine-2-yl)piperazin-1-l\}acetyl)piperazin- 1-yl]-1,4dihydroquinoline-3-carboxylicacid (3p)

m.p. 189-190 ${ }^{\circ}$; ${ }^{1} \mathrm{H}$ NMR (300 MHz, DMSO-D $) ~ \delta 1.18$ (t, 2H, $\left.J=7.2 \mathrm{~Hz}\right), 1.29$ (t, 2H, $J=6.9$ Hz), $2.46(\mathrm{~m}, 4 \mathrm{H}), 2.58(\mathrm{~m}, 4 \mathrm{H}), 3.05(\mathrm{~m}, 4 \mathrm{H}), 3.34(\mathrm{~m}, 2 \mathrm{H}), 3.67(\mathrm{~m}, 4 \mathrm{H}), 3.77(\mathrm{tt}, 1 \mathrm{H}, J=7.2$ $\mathrm{Hz}, J=6.9 \mathrm{~Hz}), 7.01(\mathrm{t}, 1 \mathrm{H}), 7.55\left(\mathrm{~d}, 1 \mathrm{H}, J_{\mathrm{H}-\mathrm{F}}=7.5 \mathrm{~Hz}\right), 7.89\left(\mathrm{~d}, 1 \mathrm{H}, J_{\mathrm{H}-\mathrm{F}}=13.2 \mathrm{~Hz}\right), 8.31(\mathrm{~d}$, $2 \mathrm{H}, J=4.6 \mathrm{~Hz}), 8.63(\mathrm{~s}, 1 \mathrm{H}), 15.18(\mathrm{~s}, 1 \mathrm{H}) .{ }^{13} \mathrm{C} \mathrm{NMR}\left(100.61 \mathrm{MHz}, \mathrm{CDCl}_{3}\right) \delta 176.82\left(\mathrm{~d}, J_{\mathrm{C}-\mathrm{F}}=\right.$ $2.2 \mathrm{~Hz}), 167.56,166.43,160.67,154.89,153.21\left(\mathrm{~d}, J_{\mathrm{C}-\mathrm{F}}=249.3 \mathrm{~Hz}\right), 147.23,145.12\left(\mathrm{~d}, J_{\mathrm{C}-\mathrm{F}}=\right.$ $10.3 \mathrm{~Hz}), 138.95,122.45,119.91\left(\mathrm{~d}, J_{\mathrm{C}-\mathrm{F}}=8.1 \mathrm{~Hz}\right), 111.97\left(\mathrm{~d}, J_{\mathrm{C}-\mathrm{F}}=24.14 \mathrm{~Hz}\right), 107.12,104.89$ $\left(\mathrm{d}, J_{\mathrm{C}-\mathrm{F}}=3.7 \mathrm{~Hz}\right), 54.12,52.23,51.08,49.67,44.97,36.24,8.14$. ESI-MS $(\mathrm{m} / z)$ :calcd. for $\mathrm{C}_{27} \mathrm{H}_{30} \mathrm{FN}_{7} \mathrm{O}_{4}$ 535.23, found $536.39[\mathrm{M}+\mathrm{H}]^{+}$.

1-cyclopropyl-7-[4-(2-\{4-(3,4-dimethoxyphenyl)piperazin-1-yl\}acetyl)piperazin-1-yl]-6-fluoro-4oxo-1,4-dihydroquinoline-3-carboxylicacid (3q)

m.p. 189-190 ${ }^{\circ} \mathrm{C} ;{ }^{1} \mathrm{H}$ NMR (300 MHz, DMSO-D $) \delta 1.18(\mathrm{t}, 2 \mathrm{H}, J=7.2 \mathrm{~Hz}), 1.29$ (t, 2H, J = 6.9 Hz), 2.35 (m, 4H), 2.42 (m, 4H), 3.25 (m, 4H), 3.38 (m, 2H), 3.71 (m, 4H), 3.73 (s, 6H), 3.79 (tt, $1 \mathrm{H}, J=7.2 \mathrm{~Hz}, J=6.9 \mathrm{~Hz}), 6.25(\mathrm{~s}, 1 \mathrm{H}), 6.56(\mathrm{~d}, 1 \mathrm{H}), 6.63(\mathrm{~d}, 1 \mathrm{H}), 7.55\left(\mathrm{~d}, 1 \mathrm{H}, J_{\mathrm{H}-\mathrm{F}}=7.5 \mathrm{~Hz}\right)$, $7.89\left(\mathrm{~d}, 1 \mathrm{H}, J_{\mathrm{H}-\mathrm{F}}=13.2 \mathrm{~Hz}\right), 8.63(\mathrm{~s}, 1 \mathrm{H}), 15.18(\mathrm{~s}, 1 \mathrm{H}) \cdot{ }^{13} \mathrm{C} \mathrm{NMR}\left(100.61 \mathrm{MHz}, \mathrm{CDCl}_{3}\right) \delta$ $176.82\left(\mathrm{~d}, J_{\mathrm{C}-\mathrm{F}}=2.2 \mathrm{~Hz}\right), 167.56,166.43,153.21\left(\mathrm{~d}, J_{\mathrm{C}-\mathrm{F}}=249.3 \mathrm{~Hz}\right), 147.23,145.12\left(\mathrm{~d}, J_{\mathrm{C}-\mathrm{F}}=\right.$ $10.3 \mathrm{~Hz}), 143.24,140.67,138.08,138.95,121.78,116.02,119.91$ (d, $\left.J_{\mathrm{C}-\mathrm{F}}=8.1 \mathrm{~Hz}\right), 117.32$, $111.97\left(\mathrm{~d}, J_{\mathrm{C}-\mathrm{F}}=24.14 \mathrm{~Hz}\right), 107.12,104.89\left(\mathrm{~d}, J_{\mathrm{C}-\mathrm{F}}=3.7 \mathrm{~Hz}\right), 61.45,60.95,59.34,53.35,51.92$, 50.65, 49.45, 35.33, 8.26. ESI-MS (m/z):calcd. for $\mathrm{C}_{31} \mathrm{H}_{36} \mathrm{FN}_{5} \mathrm{O}_{6} 593.26$, found $594.39[\mathrm{M}+\mathrm{H}]^{+}$. 
1-cyclopropyl-6-fluoro-7-[4-(2-\{4-(3-hydroxyphenyl)piperazin-1-yl\}acetylpiperazin-1-yl]-4-oxo-1,4dihydroquinoline-3-carboxylicacid (3r)

m.p. 220-222 ${ }^{\circ}$ C; ${ }^{1} \mathrm{H}$ NMR (300 MHz, DMSO-D 6 ) $\delta 1.18$ (t, 2H, $J=7.2 \mathrm{~Hz}$ ), 1.29 (t, 2H, $J=6.9$ Hz), $2.32(\mathrm{~m}, 4 \mathrm{H}), 2.43(\mathrm{~m}, 4 \mathrm{H}), 3.34(\mathrm{~m}, 4 \mathrm{H}), 3.46(\mathrm{~m}, 2 \mathrm{H}), 3.67(\mathrm{~m}, 4 \mathrm{H}), 3.81(\mathrm{tt}, 1 \mathrm{H}, J=7.2$ $\mathrm{Hz}, J=6.9 \mathrm{~Hz}), 5.23(\mathrm{~s}, 1 \mathrm{H}), 6.39(\mathrm{~d}, 1 \mathrm{H}), 6.45(\mathrm{~s}, 1 \mathrm{H}), 6.52(\mathrm{~d}, 1 \mathrm{H}), 7.05(\mathrm{t}, 1 \mathrm{H}), 7.52(\mathrm{~d}, 1 \mathrm{H}$, $\left.J_{\mathrm{H}-\mathrm{F}}=7.5 \mathrm{~Hz}\right), 7.89\left(\mathrm{~d}, 1 \mathrm{H}, J_{\mathrm{H}-\mathrm{F}}=13.2 \mathrm{~Hz}\right), 8.63(\mathrm{~s}, 1 \mathrm{H}), 15.18(\mathrm{~s}, 1 \mathrm{H}) .{ }^{13} \mathrm{C} \mathrm{NMR}(100.61 \mathrm{MHz}$, $\left.\mathrm{CDCl}_{3}\right) \delta 176.82\left(\mathrm{~d}, J_{\mathrm{C}-\mathrm{F}}=2.2 \mathrm{~Hz}\right), 167.56,166.43,153.21\left(\mathrm{~d}, J_{\mathrm{C}-\mathrm{F}}=249.3 \mathrm{~Hz}\right), 147.23,146.58$, $145.12\left(\mathrm{~d}, J_{\mathrm{C}-\mathrm{F}}=10.3 \mathrm{~Hz}\right), 142.03,138.95,134.61,119.91\left(\mathrm{~d}, J_{\mathrm{C}-\mathrm{F}}=8.1 \mathrm{~Hz}\right), 111.97\left(\mathrm{~d}, J_{\mathrm{C}-\mathrm{F}}=\right.$ $24.14 \mathrm{~Hz}), 107.28,107.12,106.07,104.89\left(\mathrm{~d}, J_{\mathrm{C}-\mathrm{F}}=3.7 \mathrm{~Hz}\right), 101.72$, 54.15, 50.91, 51.27, 49.81, 44.73, 35.99, 8.12. ESI-MS (m/z):calcd. for $\mathrm{C}_{29} \mathrm{H}_{32} \mathrm{FN}_{5} \mathrm{O}_{5} 549.24$, found $550.45[\mathrm{M}+\mathrm{H}]^{+}$.

1-cyclopropyl-7-[4-(2-\{4-(3,4-difluorophenyl)piperazin-1-yl\}acetyl)piperazin-1-yl]-6-fluoro4-oxo-1,4-dihydroquinoline-3-carboxylicacid (3s)

m.p. $198-200^{\circ} \mathrm{C} ;{ }^{1} \mathrm{H}$ NMR (300 MHz, DMSO-D $) \delta 1.24$ (t, 2H, $J=7.2 \mathrm{~Hz}$ ), 1.37 (t, 2H, $J=6.9$ $\mathrm{Hz}), 2.32(\mathrm{~m}, 4 \mathrm{H}), 2.56(\mathrm{~m}, 4 \mathrm{H}), 3.35(\mathrm{~m}, 4 \mathrm{H}), 3.39(\mathrm{~m}, 2 \mathrm{H}), 3.79(\mathrm{~m}, 4 \mathrm{H}), 3.85(\mathrm{tt}, 1 \mathrm{H}, J=7.2$ $\mathrm{Hz}, J=6.9 \mathrm{~Hz}), 6.98\left(\mathrm{dd}, 1 \mathrm{H}, J_{\mathrm{H}-\mathrm{F}}=7.1 \mathrm{~Hz}\right), 7.15\left(\mathrm{dt}, 1 \mathrm{H}, J_{\mathrm{H}-\mathrm{F}}=13.2 \mathrm{~Hz}, 6.8 \mathrm{~Hz}\right), 7.25(\mathrm{dd}, 1 \mathrm{H}$, $\left.J_{\mathrm{H}-\mathrm{F}}=12.11 \mathrm{~Hz}, 7.01 \mathrm{~Hz}\right), 7.63\left(\mathrm{~d}, 1 \mathrm{H}, J_{\mathrm{H}-\mathrm{F}}=7.5 \mathrm{~Hz}\right), 7.97\left(\mathrm{~d}, 1 \mathrm{H}, J_{\mathrm{H}-\mathrm{F}}=13.2 \mathrm{~Hz}\right), 8.71(\mathrm{~s}, 1 \mathrm{H})$, $15.22(\mathrm{~s}, 1 \mathrm{H}) .{ }^{13} \mathrm{C}$ NMR $\left(100.61 \mathrm{MHz}, \mathrm{CDCl}_{3}\right) \delta 176.82\left(\mathrm{~d}, J_{\mathrm{C}-\mathrm{F}}=2.2 \mathrm{~Hz}\right), 167.56,166.43$, $162.58\left(\mathrm{dd}, J_{\mathrm{C}-\mathrm{F}}=252.67 \mathrm{~Hz}, 22.68 \mathrm{~Hz}\right), 153.21\left(\mathrm{~d}, J_{\mathrm{C}-\mathrm{F}}=249.3 \mathrm{~Hz}\right), 151.52\left(\mathrm{dd}, J_{\mathrm{C}-\mathrm{F}}=247.28\right.$ $\mathrm{Hz}, 21.39 \mathrm{~Hz}), 147.23,145.12\left(\mathrm{~d}, J_{\mathrm{C}-\mathrm{F}}=10.3 \mathrm{~Hz}\right), 141.49\left(\mathrm{~d}, J_{\mathrm{C}-\mathrm{F}}=2.8 \mathrm{~Hz}\right), 138.95,125.23(\mathrm{~d}$, $\left.J_{\mathrm{C}-\mathrm{F}}=3.07 \mathrm{~Hz}\right), 119.91\left(\mathrm{~d}, J_{\mathrm{C}-\mathrm{F}}=8.1 \mathrm{~Hz}\right), 111.97\left(\mathrm{~d}, J_{\mathrm{C}-\mathrm{F}}=24.14 \mathrm{~Hz}\right), 110.87\left(\mathrm{dd}, J_{\mathrm{C}-\mathrm{F}}=23.81\right.$ $\mathrm{Hz}, 3.7 \mathrm{~Hz}), 109.42\left(\mathrm{dd}, J_{\mathrm{C}-\mathrm{F}}=20.65 \mathrm{~Hz}, 2.95 \mathrm{~Hz}\right), 107.12,104.89\left(\mathrm{~d}, J_{\mathrm{C}-\mathrm{F}}=3.7 \mathrm{~Hz}\right), 55.32$, 51.49, 51.11, 49.72, 45.29, 35.37, 8.42. ESI-MS (m/z):calcd. for $\mathrm{C}_{29} \mathrm{H}_{30} \mathrm{~F}_{3} \mathrm{~N}_{5} \mathrm{O}_{4} 569.22$, found $570.49[\mathrm{M}+\mathrm{H}]^{+}$.

7-[4-(2-\{4-(bis(4-fluoroophenyl)methyl)piperazin-1-yl\}acetyl)piperazin-1-yl]-1-cyclo propyl-6fluoro-4-oxo-1,4-dihydroquinoline-3-carboxylicacid (3t)

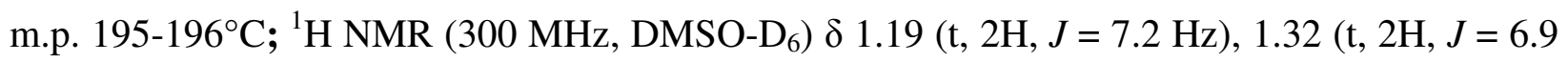
Hz), 2.39 (m, 4H), $2.56(\mathrm{~m}, 4 \mathrm{H}), 3.25(\mathrm{~m}, 4 \mathrm{H}), 3.35(\mathrm{~m}, 2 \mathrm{H}), 3.74(\mathrm{~m}, 4 \mathrm{H}), 3.86(\mathrm{tt}, 1 \mathrm{H}, J=7.2$ 
$\mathrm{Hz}, J=6.9 \mathrm{~Hz}), 4.2(\mathrm{~s}, 1 \mathrm{H}), 7.13-7.21\left(\mathrm{dd}, 4 \mathrm{H}, J_{\mathrm{H}-\mathrm{F}}=8.5 \mathrm{~Hz}\right), 7.42-7.5\left(\mathrm{dd}, 4 \mathrm{H}, J_{\mathrm{H}-\mathrm{F}}=5.8 \mathrm{~Hz}\right.$, $\left.J_{\mathrm{H}-\mathrm{F}}=7.5 \mathrm{~Hz}\right) 7.59-7.61\left(\mathrm{~d}, 1 \mathrm{H}, J_{\mathrm{H}-\mathrm{F}}=7.5 \mathrm{~Hz}\right), 7.94-7.99\left(\mathrm{~d}, 1 \mathrm{H}, J_{\mathrm{H}-\mathrm{F}}=13.2 \mathrm{~Hz}\right), 8.71(\mathrm{~s}, 1 \mathrm{H})$, $15.22(\mathrm{~s}, 1 \mathrm{H}) .{ }^{13} \mathrm{C}$ NMR $\left(100.61 \mathrm{MHz}, \mathrm{DMSO}-\mathrm{D}_{6}\right) \delta 176.97\left(\mathrm{~d}, J_{\mathrm{C}-\mathrm{F}}=2.2 \mathrm{~Hz}\right), 168.23,166.76$, $161.83\left(\mathrm{~d}, J_{\mathrm{C}-\mathrm{F}}=246.49 \mathrm{~Hz}\right), 153.57\left(\mathrm{~d}, J_{\mathrm{C}-\mathrm{F}}=251.52 \mathrm{~Hz}\right), 147.50,145.45(\mathrm{~d},=10.3 \mathrm{~Hz})$, $139.01,138.07\left(\mathrm{~d}, J_{\mathrm{C}-\mathrm{F}}=2.9 \mathrm{~Hz}\right), 129.21\left(\mathrm{~d}, J_{\mathrm{C}-\mathrm{F}}=7.3 \mathrm{~Hz}\right), 120.08\left(\mathrm{~d}, \mathrm{~d}, J_{\mathrm{C}-\mathrm{F}}=8.1 \mathrm{~Hz}\right), 115.43$ $\left(\mathrm{d}, J_{\mathrm{C}-\mathrm{F}}=21.27 \mathrm{~Hz}\right), 112.46\left(\mathrm{~d}, J_{\mathrm{C}-\mathrm{F}}=23.48 \mathrm{~Hz}\right), 108.11,105.05\left(\mathrm{~d}, J_{\mathrm{C}-\mathrm{F}}=3.7 \mathrm{~Hz}\right), 74.43,53.31$, 51.70, 50.61, 49.39, 45.45, 35.32, 8.25. ESI-MS ( $/ 2 / z)$ :calcd. for $\mathrm{C}_{36} \mathrm{H}_{36} \mathrm{~F}_{3} \mathrm{~N}_{5} \mathrm{O}_{4} 659.27$, found $660.62[\mathrm{M}+\mathrm{H}]^{+}$.

1-cyclopropyl-7-[4-(2-\{4-(2-(dimethylamino)ethyl)piperazin-1-yl\}acetyl)piperazin-1-yl]-6-fluoro-4oxo-1,4-dihydroquinoline-3-carboxylicacid ( $3 \boldsymbol{u})$

m.p. $138-140^{\circ} \mathrm{C} ;{ }^{1} \mathrm{H}$ NMR (300 MHz, DMSO-D 6 ) $\delta 1.24$ (t, $2 \mathrm{H}, J=7.2 \mathrm{~Hz}$ ), 1.37 (t, 2H, $J=6.9$ Hz), $2.42(\mathrm{~m}, 4 \mathrm{H}), 2.59(\mathrm{~m}, 4 \mathrm{H}), 2.70(\mathrm{t}, 4 \mathrm{H}), 2.83(\mathrm{~s}, 6 \mathrm{H}), 3.35(\mathrm{~m}, 4 \mathrm{H}), 3.39(\mathrm{~m}, 2 \mathrm{H}), 3.76(\mathrm{~m}$, $4 \mathrm{H}), 3.89(\mathrm{tt}, 1 \mathrm{H}, J=7.2 \mathrm{~Hz}, J=6.9 \mathrm{~Hz}), 7.63\left(\mathrm{~d}, 1 \mathrm{H}, J_{\mathrm{H}-\mathrm{F}}=7.5 \mathrm{~Hz}\right), 7.97\left(\mathrm{~d}, 1 \mathrm{H}, J_{\mathrm{H}-\mathrm{F}}=13.2\right.$ $\mathrm{Hz}), 8.71(\mathrm{~s}, 1 \mathrm{H}), 15.22(\mathrm{~s}, 1 \mathrm{H}) .{ }^{13} \mathrm{C} \mathrm{NMR}\left(100.61 \mathrm{MHz}, \mathrm{CDCl}_{3}\right) \delta 176.82\left(\mathrm{~d}, J_{\mathrm{C}-\mathrm{F}}=2.2 \mathrm{~Hz}\right)$, 167.56, 166.43, $153.21\left(\mathrm{~d}, J_{\mathrm{C}-\mathrm{F}}=249.3 \mathrm{~Hz}\right), 147.23,145.12\left(\mathrm{~d}, J_{\mathrm{C}-\mathrm{F}}=10.3 \mathrm{~Hz}\right), 138.95,119.91$ $\left(\mathrm{d}, J_{\mathrm{C}-\mathrm{F}}=8.1 \mathrm{~Hz}\right), 111.97\left(\mathrm{~d}, J_{\mathrm{C}-\mathrm{F}}=24.14 \mathrm{~Hz}\right), 107.12,104.89\left(\mathrm{~d}, J_{\mathrm{C}-\mathrm{F}}=3.7 \mathrm{~Hz}\right), 60.95,53.53$, 51.67, 50.22, 49.20, 48.63, 47.97, 41.11, 35.12, 8.09. ESI-MS (m/z):calcd. for $\mathrm{C}_{27} \mathrm{H}_{37} \mathrm{FN}_{6} \mathrm{O}_{4}$ 528.29, found $530.41[\mathrm{M}+\mathrm{H}]^{+}$.

1-cyclopropyl-6-fluoro-4-oxo-7-[4-(2-\{4-(3-(trifluoromethyl)phenyl)piperazin-1-yl\} acetyl)piperazin-1-yl]-1,4-dihydroquinoline-3-carboxylicacid (3v) m.p. 190-192 ${ }^{\circ}$ C; ${ }^{1} \mathrm{H}$ NMR (300 MHz, DMSO-D 6 ) $\delta 1.24$ (t, $2 \mathrm{H}, J=7.2 \mathrm{~Hz}$ ), 1.37 (t, 2H, $J=6.9$ Hz), 2.42 (m, 4H), $2.59(\mathrm{~m}, 4 \mathrm{H}), 3.35$ (m, 4H), 3.39 (m, 2H), $3.76(\mathrm{~m}, 4 \mathrm{H}), 3.89$ (tt, $1 \mathrm{H}, J=7.2$ $\mathrm{Hz}, J=6.9 \mathrm{~Hz}), 7.14(\mathrm{~d}, 1 \mathrm{H}, 7.78 \mathrm{~Hz}), 7.26(\mathrm{~s}, 1 \mathrm{H}), 7.30(\mathrm{~d}, 1 \mathrm{H}, 8.3 \mathrm{~Hz}), 7.48(\mathrm{t}, 1 \mathrm{H}, 8.03 \mathrm{~Hz})$, $7.63\left(\mathrm{~d}, 1 \mathrm{H}, J_{\mathrm{H}-\mathrm{F}}=7.5 \mathrm{~Hz}\right), 7.97\left(\mathrm{~d}, 1 \mathrm{H}, J_{\mathrm{H}-\mathrm{F}}=13.2 \mathrm{~Hz}\right), 8.71(\mathrm{~s}, 1 \mathrm{H}), 15.22(\mathrm{~s}, 1 \mathrm{H}) .{ }^{13} \mathrm{CNMR}$ $\left(100.61 \mathrm{MHz}, \mathrm{CDCl}_{3}\right) \delta 176.82\left(\mathrm{~d}, J_{\mathrm{C}-\mathrm{F}}=2.2 \mathrm{~Hz}\right), 167.56,166.43,153.21\left(\mathrm{~d}, J_{\mathrm{C}-\mathrm{F}}=249.3 \mathrm{~Hz}\right)$, $148.38\left(\mathrm{~d}, J_{\mathrm{C}-\mathrm{F}}=249.3 \mathrm{~Hz}\right), 147.23,145.12\left(\mathrm{~d}, J_{\mathrm{C}-\mathrm{F}}=10.3 \mathrm{~Hz}\right), 138.95,132.94,126.39,124.62$, $119.91\left(\mathrm{~d}, J_{\mathrm{C}-\mathrm{F}}=8.1 \mathrm{~Hz}\right), 119.19,116.47,112.72,111.97\left(\mathrm{~d}, J_{\mathrm{C}-\mathrm{F}}=24.14 \mathrm{~Hz}\right), 107.12,104.89(\mathrm{~d}$, $\left.J_{\mathrm{C}-\mathrm{F}}=3.7 \mathrm{~Hz}\right), 54.11,50.89,50.16,49.92,45.14,35.49,8.08$. ESI-MS $(\mathrm{m} / \mathrm{z})$ :calcd. for $\mathrm{C}_{30} \mathrm{H}_{31} \mathrm{~F}_{4} \mathrm{~N}_{5} \mathrm{O}_{4} 601.23$, found $602.56[\mathrm{M}+\mathrm{H}]^{+}$ 
